\title{
NEW ROSES VARIETIES OBTAINED AT HORTICULTURAL RESEARCH STATION CLUJ, ROMANIA
}

\author{
Gabriela Roman $^{1}$, Eugenia Harsan ${ }^{1, *}$, Ulian Besleaga ${ }^{1}$, Zoltan Felfoldi ${ }^{1}$ \\ ${ }^{1}$ University of Agricultural Sciences and Veterinary Medicine Cluj-Napoca, Romania
}

\begin{abstract}
Rosa $L$ is an excellent landscaping plant, famous for the diversity of colors, perfumes and shapes At the Horticulture Research Station Cluj, Romania (USAMV -HRS Cj), in 2018-2020, two new landscape rose cultivars, Puritate and Bogdana was evaluated the decorative value, the resistance to frost and diseases. For ornamental traits was appreciated the flowers color, the plants' habitus, the flowering waves and the way of using the cultivars in various landscaping situations. The decorative value was determined on the basis of three years evaluation. Fourteen characteristics were analyzed according to the group to which each cultivar belongs all cultivars presented valuable characteristics, for both decorative traits and response to ecological conditions. These cultivars can be used in various landscaping situations like borders, massifs, hedges, small covered groups and also as cut flowers
\end{abstract}

Keywords: breeding, cultivar, landscape roses.

\section{INTRODUCTION}

In Romania, rose growing is much appreciated by the people and the specialists and through research work, remarkable results were obtained to establish the range of cultivars in the study of resistance to frost and diseases, in micropropagation, in establishing the necessary global temperatures for flowering and in creating new cultivars well adapted to the specific conditions (Wagner, 2002; Ardelean et.al., 2006). The objective of the rose breeding. For obtaining new cultivars they were used as genitors over 430 cultivars with good resistance to disease and frost, from the mentioned group from breeders experience there are remarkable achievements in obtaining roses "without problems", with attractive foliage, outstanding colors and shapes and good resistance too. (Wagner, 1999; Sestras et.al., 2008).

\section{MATERIALS AND METHODS}

The biologic material, the two new cultivars, Puritate and Bogdana, was selected from the selection land, between 2018-2020. To evaluate the decorative value of the cultivars, the method used was suggested by Polocsay (1966), during three years, assessments were done upon 14 characteristics according to the group of cultivars. Each characteristic had a benchmark score and the total number of points that could be attained for each analyzed trait was 100. It was considered that some cultivars that gather, on average, a score superior to 70 ; in three years, could be considered valuable for crop and suitable in the growing process. Also, the characteristic was evaluated as the modern guide. 


\section{Current Trends in Natural Sciences}

Vol. 10, Issue 19, pp. 89-91, 2021

https://doi.org/10.47068/ctns.2021.v10i19.011

Current Trends in Natural Sciences (on-line)

ISSN: 2284-953X

Current Trends in Natural Sciences (CD-Rom)

ISSN: 2284-9521

ISSN-L: 2284-9521

ISSN-L: 2284-9521

\section{RESULTS AND DISCUSSIONS}

The principal characteristics of the new rose cultivars. The principal morphological characteristics of the rose cultivars and the evaluation scores for some traits are presented in 1-3 tables based on the registered data, there could be formulated the general characteristics of the analyzed cultivars.

Table 1. The main morphological characteristics of the two rose cultivars

\begin{tabular}{|l|l|l|l|l|l|l|l|}
\hline \multirow{2}{*}{ Cultivar } & \multicolumn{3}{|c|}{ The bush } & \multicolumn{2}{c|}{ The flower } & \multicolumn{2}{c|}{ Flowering } \\
\cline { 2 - 8 } & habitus & $\begin{array}{l}\text { height } \\
(\mathbf{m})\end{array}$ & $\begin{array}{l}\text { diameter } \\
(\mathbf{m})\end{array}$ & Type & Color & Beginning of blooms & Wawes \\
\hline Bogdana & Semi-erect & 0.53 & 0.20 & Involutes & Purple & Early & Perpetual \\
\hline Puritate & Erect & 0.90 & 0.80 & Semi-involutes & White & Mid-early & Perpetual \\
\hline
\end{tabular}

Table 2 Aspects related to flowering

\begin{tabular}{|l|l|l|}
\hline \multirow{2}{*}{ Cultivar } & Flowering \\
\cline { 2 - 3 } & Beginning of blooms & Wawes \\
\hline Bogdana & Early & Perpetual \\
\hline Puritate & Mid-early & Perpetual \\
\hline
\end{tabular}

Table 3 Resistance and cultivar uses

\begin{tabular}{|l|l|l|l|}
\hline Cultivar & The flower frost resistance & Disease resistance & Cultivar uses \\
\hline Bogdana & resistant & resistant & rebates, parks, gardens \\
\hline Puritate & resistant & resistant & parks, gardens \\
\hline
\end{tabular}

Tabel 4 Table of cultivars Characteristics

\begin{tabular}{|l|l|l|l|l|}
\hline \multirow{2}{*}{ No.crt. } & Cultivar & Bogdana & Puritate \\
\cline { 2 - 5 } & Characteristic & Benchmark score & Score & Score \\
\hline 1. & Shrub shape & 5 & 4.0 & 4.2 \\
\hline 2. & Vigor & 10 & 8.3 & 8.7 \\
\hline 3. & Foliage & 10 & 8.4 & 8.2 \\
\hline 4. & Disease resistance & 8 & 7.8 & 7.8 \\
\hline 5. & Flower steam and peduncle & 5 & 4.6 & 4.9 \\
\hline 6. & Flowering intensity & 10 & 6.8 & 6.6 \\
\hline 7. & Inflorescence & 5 & 4.1 & 4.0 \\
\hline 8. & Bud shape & 5 & 3.3 & 4.3 \\
\hline 9. & Flower shape & 9 & 8.0 & 8.0 \\
\hline 10. & Flower durability & 9 & 6.2 & 5.6 \\
\hline 11. & Falling petals & 5 & 4.1 & 4.0 \\
\hline 12. & Bud color & 6 & 6.0 & 6.0 \\
\hline 13. & Flower color & 6 & 5.0 & 5.1 \\
\hline 14. & Fragrance & 7 & 4.0 & 3.3 \\
\hline TOTAL & & $\mathbf{1 0 0}$ & $\mathbf{8 0 . 6}$ & $\mathbf{8 0 . 7}$ \\
\hline
\end{tabular}

Habitus: Among the analyzed cultivar Puritate is upright with a height between $0.85-0.90 \mathrm{~m}$ and Bogdana is semi- upright with a height of $0.63 \mathrm{~m}$, table1.

Vigour: Puritate is an cultivar with high vigour, Bogdana with midle vigour.

Color|: Bogdana is purplish and Puritate is white, useful for diversifying of rose assortment.

The flower: Regarding flower type cultivars Bogdana has involutes flowers and Puritate cultivar has semi -involutes flowers. 
Flowering: It begins in the first days of June among the cultivars presented, Bogdana blooms early and Puritate semi - early.

Flowering waves was the studied for the cultivars, both of them are flowering perpetual

Frost hardiness: It is an extremely important characteristic for continental temperate climate regions, where temperatures could drop in the winter below $-20 \mathrm{C}$. It was established for all the cultivars, protected by mounding during winter, by using a score of $1-4$, in which " 1 " is very sensitive and ' 4 "' is resistant to frost, both cultivars were noted as resistant.

Both cultivars, Bogdana and Puritate are suitable and recommended for landscaping for parks, gardens, borders and small groups.

Diseases hardiness: It was found that the new cultivars are tolerant resistant to mildew, black spot diseases and Aphids and Japanese Beetles pests A brief description and resume of the new cultivars obtained in the years $2018-2020$.

\section{PURITATE AND BOGDANA}

Bogdana : This cultivar belongs to shrub group, it was homologated in the year 2011 by Gabriela Roman and Stefan Wagner authors. It originates from the hybrid combination Candy Rosa $\mathrm{x}$ Yesterday. Its shrub is of average vigor, with involutes, purple mauve flowers. It has continuous flowering, very good resistance to frost and mildew, black spot diseases and Aphids and Japanese Beetles pests. It is suitable for parks, in groups and flower bands.

Puritate : These cultivars belong, to the bed group. It was homologated in the year 2012, the authors are Gabriela Roman and Wagner Stefan. It originates from the hybrid combination Rusticana $x$ Lavender Dream. The shrub is big, vigorous with semi-involutes and white color flowers. It has continuous flowering, very good resistance to frost and mildew, black spot diseases and Aphids and Japanese Beetles pests. It is suitable for parks and gardens. These homologated cultivars are extended in culture and required by private producers and state institutions.

\section{CONCLUSIONS}

Between 2018 and 2020 U.S.A.M.V. - H.R.S. Cluj Researchers studied two new cultivars, Bogdana and Puritate, which are now used in culture. The decorative value was determined on the basis of three years evaluation. Fourteen characteristics were analyzed according to the group to which each cultivar belongs all cultivars presented valuable characteristics, for both decorative traits and response to ecological conditions.

\section{ACKNOWLEDGEMENTS}

These cultivars can be used in various landscaping situations like borders, massifs, hedges, small covered groups and also as cut flowers.

\section{REFERENCES}

Kanwaljeet Singh, Yash Pal Sharma, Sumeet Gairola (2020) Morphological characterization of wild Rosa L. germplasm from the Western Himalaya, India, Euphytica 216, 41, https://doi.org/10.1007/s10681-020-2567-2

List all guidelines by TG reference, 2010, 2011, https://www.upov.int/test_guidelines/en/list.jsp

Polocsay, R. (1966 ) My flower breeding experiments ( in Romanian ), Ed. Agrosilvica Bucuresti, pp .84-90

Wagner., St. (2002) The rose from myth to the third millennium (in Romanian ) Cluj- Napoca, pp .158-178

Wagner., St. and V. Raureanu (1996). The main rose diseases and pests and the fighting against them (in Romanian ). Rev. Rosarium, 1, 5-10.

Wagner., St. Ardeleanu., R. Sestras., V. Ghidra., D. Pamfil., G. Roman., A. Florincescu, M. Cordea., C. Catana and V. Budiu (2000) Achievements in rose breeding at Cluj-Napoca, Romania in the last thirty years, Biotechnol and Biotehnol, 2, 37-41. 